\title{
O PODER DISCIPLINAR ENQUANTO UMA DIMENSÃO DA CULTURA \\ ORGANIZACIONAL: UM ESTUDO MULTICASOS EM INSTITUIÇÕES DE ENSINO SUPERIOR PRIVADAS
}

THE DISCIPLINARY POWER AS A DIMENSION OF ORGANIZATIONAL CULTURE: A MULTICASE STUDY IN PRIVATE HIGHER EDUCATION INSTITUTIONS

\author{
Recebido em: 12/08/2017 - Aprovado em: 23/10/2017 \\ Avaliado pelo sistema double blind review \\ Editor Científico: Edson Sadao Iizuka \\ DOI 10.13058/raep.2018.v19n1.731
}

\section{ANDRÉMAURÍCIO TEIXEIRA DA SILVA andremtsilva@yahoo.com MARIANE LEMOS LOURENÇO}

UNIVERSIDADE FEDERAL DO PARANÁ

\section{RESUMO}

Este artigo teve como objetivo geral investigar como se manifesta e é interpretado, pelos docentes, o poder disciplinar em face dos elementos da cultura organizacional em instituições de ensino superior (IES) privadas. Foi realizado um estudo multicasos, em IES privadas na região Sul do Brasil, pelo qual se priorizou a análise do discurso organizacional no estabelecimento dos conceitos, dos objetos e na posição dos sujeitos nesse discurso e das suas ações com relação às práticas de produção, transmissão e consumo de textos que reforcem, alterem ou resistam ao discurso. Destacou-se, dentre os achados, a precarização do trabalho docente nesse contexto, em que o professor passa a ser um mero executor de programas de ensino com reduzida autonomia e controle das suas atividades. Aliado a isso, ainda, passa a incorporar as atividades de promoção e manutenção das instituições com o intuito de agradar os clientes e o mercado de atuação. Tudo isso realizado sobre uma estrita vigilância e controle por parte das instituições e dos alunos. Este trabalho contribui no sentido de elucidar a situação dos professores no Ensino Superior privado, pois fornece uma compreensão a partir das suas próprias interpretações e experiências.

Palavras-chave: Cultura organizacional. Poder disciplinar. Vigilância no trabalho. Trabalho docente.

\begin{abstract}
This article had the general objective of investigating how the disciplinary power is manifested and interpreted by teachers in the face of the elements of the organizational culture in private higher education institutions. A multicase study was carried out in Private Higher Education Institutions in the southern region of Brazil, in which it was prioritized the analysis of the organizational discourse in the establishment of the concepts, objects, and the position of the subjects within this discourse, as well as the subject's actions regarding the practices of production, transmission, and consumption of texts that reinforce, alter, or resist that discourse. Main findings show the weakening of teaching work in this context, where the teacher becomes a mere executor of teaching programs with reduced autonomy and control of their activities. Moreover, teachers start to incorporate the activities of promotion and maintenance of institutions by means of trying to please customers and the market field. All these facts are carried out under strict supervision and control by institutions and students. This work contributes to elucidating the situation of teachers in private higher education by providing an understanding from their own interpretations and experience.

Keywords: Organizational culture. Disciplinary power. Workplace surveillance. Teaching work.
\end{abstract}




\section{INTRODUÇÃO}

O trabalho acadêmico de docentes em Instituições de Ensino Superior (IES) é tema de constantes debates acerca do que leva certas pessoas a exercer essa carreira e do contexto e das condições em que esse tipo de trabalho é desenvolvido (BASTOS, 2007; FREITAS, 2007a, 2007b). Nas IES privadas, adiciona-se, aos complexos arranjos de demandas e sistemáticas de controle e desempenho, a adequação da organização à lógica do lucro. As práticas de desempenho de outras organizações voltadas a atender demandas de mercado em termos de qualidade de serviços buscam lucratividade e resultados operacionais e financeiros. Consequentemente, essa lógica mercadológica terá reflexos no trabalho docente. A averiguação desse trabalho, por parte das IES privadas, verifica-se em um estrito cumprimento no tocante à presença em sala de aula, em seguir programas de trabalho previamente estabelecidos, muitas vezes, sem a participação do professor, ao atendimento ao cliente - nesse caso, o aluno - e outras demandas de produção e atualização acadêmica que extrapolam a organização e invadem outras áreas da vida do profissional de ensino (CLARKE; KNIGHTS, 2015).

A cultura organizacional e as ligações de poder pertencem à própria natureza das relações humanas e estão presentes nas pequenas atividades do dia a dia nas organizações. Os sujeitos, quando trabalham, interpretam e dão significados às suas ações, estão constantemente reproduzindo e produzindo relações de poder e uma cultura nas organizações (GEERTZ, 1973; ALVESSON, 2002; CLEGG et al., 2006).

O poder disciplinar visa, efetivamente, disciplinar o corpo transformando-o em útil e dócil mediante práticas diárias de vigilância própria, normalização e subjetivação voltadas para alinhar o sujeito com os objetivos instrumentais (BARKER, 1993; WILLMOTT, 1993; SEWELL, 1998; FOUCAULT, 2004; SEWELL; BARKER, 2006). Ele está articulado a um sistema cultural organizacional e geral que visa encapsular toda a vida do sujeito para a relação de trabalho (MCKINLAY et al., 2012; MUNRO, 2012; FLEMING, 2013). 
Esta pesquisa foi, então, realizada com o objetivo geral de investigar a manifestação e interpretação do poder em face dos elementos da cultura organizacional pelos professores atuantes em Instituições de Ensino Superior privadas, na região Sul do Brasil. Para tanto, foi realizado um estudo de casos múltiplos com a perspectiva temporal de corte transversal e aproximação longitudinal, sendo o nível de análise multinível entre os sujeitos, organização e contexto (STAKE, 1995; CRESWELL, 2010).

Este trabalho está estruturado por esta introdução; na sequência, há a fundamentação teórica, que aborda a cultura organizacional, o poder disciplinar e o trabalho docente em IES privadas; depois, os procedimentos metodológicos; a apresentação dos resultados da pesquisa e a análise dos dados, por fim, as considerações finais e sugestões para pesquisas futuras. 


\section{FUNDAMENTAÇÃO TEÓRICA}

\section{CULTURA ORGANIZACIONAL E PODER DISCIPLINAR}

A cultura organizacional é um tema difundido e debatido nos estudos organizacionais com início há aproximadamente 35 anos. Entretanto o tempo não significa que o tema tenha se esgotado e muito menos que haja um consenso acerca da própria definição de cultura organizacional ou de um paradigma estabelecido para sua análise, sendo que permanece como um "código de muitas cores" (JELINEK et al., 1983; GIORGI et al., 2015).

A cultura organizacional é compreendida como um sistema comum de símbolos e significados pelo qual os seres humanos interpretam suas experiências e guiam suas ações, sendo central para governar o entendimento pertinente a comportamentos, eventos, instituições e processos. Os significados socialmente partilhados referem-se a como um objeto ou uma expressão são interpretados numa organização (GEERTZ, 1973; ALVESSON, 2002).

Segundo Freitas (2007c), alguns elementos da cultura organizacional são aqueles mais tratados na produção acadêmica e empresarial e são uma releitura e "adaptação" dos conceitos antropológicos aplicados ao ambiente organizacional. Entre eles, destacam-se valores; crenças e pressupostos; ritos, rituais e cerimonias; sagas e heróis; histórias; tabus; e normas. Como complemento a esses elementos, também, destacam-se os artefatos, que são as produções materiais de uma cultura organizacional que expressam significados partilhados para seus membros (TRICE; BEYER, 1984).

Os conceitos de cultura e poder são elusivos e contestados. A relação entre esses conceitos está, segundo Engelstad (2009), na realização de instâncias de poder, dentro de um arranjo cultural próprio que se expressa de diversas formas, sendo o poder capaz de influenciar as interpretações culturais dos atores sociais direta e indiretamente. Na forma direta, os efeitos do poder são materializados num contexto cultural mediante discursos, promessas, ameaças, no enunciado de proibições, ordens e pedidos. De forma indireta, o poder atua pela persuasão no conhecimento e crenças dos atores em relação à natureza do mundo e da concepção de como esse mundo 
deve ser em termos de normas, valores, preferências pessoais e lealdades políticas (ENGELSTAD, 2009).

A análise da cultura organizacional, baseada nos conceitos da analítica de poder de Foucault, passa, então, a buscar a formação dos discursos de forma contingencial através da história na relação de produção do poder e do conhecimento. O método da analítica de poder de Foucault é uma "história do presente" que busca traçar as conexões do arbitrário e do acidental nas práticas correntes. Essas conexões apresentam-se como redes de relações, práticas, discursos e instituições que são repetidas e acabam por ser internalizadas pelo sujeito sem a consciência de seu propósito original (CALAS; SMIRCICH, 1999). Desse modo, o discurso organizacional em relação à cultura é composto por um novo vocabulário de trabalho em equipe, qualidade, flexibilidade e aprendizado organizacional que constituem projetos de administração da cultura que representam o desejo de alistar os empregados para cooperar, comprometer-se e conformar-se com um esprit de corps (CHAN; CLEGG, 2002).

A cultura organizacional molda, então, certa subjetividade nos sujeitos da organização. Essa subjetividade é especificada e imbuída com uma conduta e um comportamento específico aos fins instrumentais da organização. Os discursos dominantes da cultura organizacional procuram criar um sujeito maleável por meio do controle dos significados, incorporando e excluindo o que pode ser falado e quem pode falar, fazendo da cultura organizacional um olho vigilante. Essa vigilância é voltada para as estruturas de cognição determinadas pelas práticas e convenções linguísticas, e do contexto não linguístico que constituem a subjetividade. O sujeito/corpo manifesta os efeitos do discurso regulador da cultura organizacional nos seus hábitos, gestos, postura, fala e na expressão dos sentimentos (CHAN; CLEGG, 2002).

Nos estudos organizacionais, a cultura organizacional e as relações de poder têm sido debatidas e pesquisadas, como mostram os trabalhos de Rodriguez e Stewart (2017); Murad et al. (2017); Ramos et al. (2016); Torelli et al. (2015); Pompper (2014); Willmott (2013); Waiandt e Davel (2012); Ball e Margulis (2011); Varella et al. (2010); Castro et al. (2009), en- 
tre outros. Dessas correntes de pesquisa e formas de se compreender esses fenômenos nas organizações, adota-se aqui o sentido da cultura organizacional como um conjunto de elementos articulados que pode, por vezes, servir para instrumentalizar práticas de poder, constituído por símbolos e significados pela linguagem e, vividos, produzidos e reproduzidos na subjetividade dos sujeitos e nas interações sociais (GEERTZ, 1973; FREITAS, 2000; ALVESSON, 2002). De outra forma, a compreensão de poder é influenciada pela obra de Foucault.

O poder é uma ideia debatida nas ciências sociais desde que houve uma preocupação com a compreensão da ordem social. E isso não significa que há uma definição estabelecida do conceito de poder, muito pelo contrário, a essência do conceito é contestada, sendo que a melhor maneira de se pensar em poder não é em termos de sua essência, mas, sim, como uma ferramenta plural e moldada pelo contexto que nos possibilite criar sentido do mundo social (HARDY; CLEGG, 2001; CLEGG; HAUGAARD, 2009). Para Clegg et al. (2006), a ideia de poder esteve sempre presente na realidade das organizações, sendo mesmo considerado como o próprio ar da vida organizacional.

A forma de ação desse poder é o que se pode chamar de a face de subjetivação do poder. O foco de influência está em determinar o próprio senso de sujeito, sua constituição, suas emoções e identidade. Definir as condições possíveis que estão subjacentes na forma como o sujeito realiza a experiência de ser (FLEMING; SPICER, 2007).

Para Foucault, o poder passa a ser abordado como uma formação complexa de relações de forças originárias de diversos locais do sistema social e que estão em constante mutação formando estados de poder. $\mathrm{O}$ poder não sendo mais algo que se possa possuir, passa, então, a ser verificado no entendimento de que alguém o exerce sobre outro alguém, ou seja, numa abstração, não há poder num indivíduo sozinho, é preciso a relação para estabelecer o poder. Quando há uma relação, há poder (FOUCAULT, 1998; 1999a; 2002; 2004).

O poder disciplinar possui sua origem em Foucault, no período da genealogia, e é caracterizado pela vigilância, pelo olhar hierárquico, pela 
sanção normalizadora por meio de regras e normas, bem como pelo exame que continuamente qualifica ou desqualifica e que produz e reproduz a disciplina (FOUCAULT, 2004; 2005). Entre as técnicas de poder disciplinar, temos a vigilância entre times e pares que promovem mecanismos de automonitoramento em que o olhar vigilante é incorporado aos próprios empregados (BARKER, 1993; SEWELL; BARKER, 2006; SEWELL et al., 2012). Outras formas de conhecimentos gerenciais e discursos organizacionais, também, exercem influência disciplinar sobre a vida organizacional, como, por exemplo, as diversas técnicas de recursos humanos (BARRATT, 2003; WEISKOPF; MUNRO, 2011), de estratégia (DICK; COLLINGS, 2014) e cultura organizacional (RIAD, 2005). O discurso assume um papel de destaque nessa linha de pesquisa enquanto formador da realidade através de sistemas de textos e falas (HARDY; PHILLIPS, 2004). Existe um amplo conjunto de pesquisas nesse sentido, e um esforço de mapeamento desse corpo de pesquisas é realizado por Phillips e Oswick (2012). A organização passa a ser vista como uma construção discursiva de poder, com fins políticos de controle e construção da realidade, em um propósito específico de um conjunto de atores, que organiza e molda a realidade diária dos sujeitos (LECLERCQ-VANDELANNOITTE, 2011).

Destaca-se aqui que, contemporaneamente, há um amplo segmento de estudos caracterizados como estudos de vigilância. São estudos de natureza interdisciplinar com envolvimento de disciplinas como ciência política, direito, sociologia, psicologia, economia, administração, ciência da computação, entre outras, que buscam compreender como as práticas de vigilância influenciam os processos de ordenação social (LYON et al., 2012). No âmbito das organizações, a vigilância está relacionada com a vigilância no local de trabalho ou simplesmente vigilância no trabalho (workplace surveillance).

A vigilância é definida como um processo de coleta, registro e análise sistematizada de indivíduos, grupos ou populações e contextos por via do uso de meios técnicos, para extrair e gerar informações realizadas por indivíduos, organizações e governos (MARX, 2012; 2015). A vigilância nas organizações está ligada à capacidade da administração em monitorar, re- 
gistrar e acompanhar o desempenho, o comportamento e as características dos funcionários na própria organização ou em outros espaços (como a internet) para controlar a ascensão na hierarquia e o próprio acesso ou a permanência na organização (BALL, 2010).

São três as principais considerações que vêm ao encontro das práticas de vigilância. A primeira delas está relacionada com a base contratual da relação de trabalho. Os empregadores, de alguma forma, precisam saber se os empregados estão cumprindo com aquilo que é esperado deles e que foi estabelecido nas obrigações do contrato de trabalho. Segunda, na realidade das organizações atuais e no contexto em que está estabelecida a economia capitalista, existe uma expectativa de justiça em relação àquilo que o empregado deve receber proporcionalmente pelo seu esforço com o resultado organizacional. E, por fim, terceira, as organizações são baseadas em algum tipo de hierarquia formal com supervisão e competências definidas dentro de uma relação coordenada no tempo e espaço (SEWELL, 2012).

Sewell (2012) elabora um conceito mais integrado em quatro formas de realização da vigilância nas organizações. A primeira delas é vigilância simples e direta. É aquela realizada diretamente pelos sentidos do indivíduo, ou seja, pelo olho, pela visão (considerando aqui também aquela realizada através de câmeras de vigilância), e envolve um julgamento subjetivo da avaliação do sujeito da vigilância. A segunda é a vigilância simples e indireta. Voltada para a verificação da disposição em relação ao trabalho. Um exemplo recente envolve o monitoramento de redes sociais dos funcionários, que passa a ser utilizado com cada vez mais frequência, e é ainda sancionado institucionalmente (GOMES, 2014). A terceira vigilância é a complexa e direta. Essa vigilância é caracterizada pela utilização de métricas, análises objetivas com relação a desempenho e produtividade que podem fornecer meios de comparar um empregado em relação a outros. A quarta e última vigilância é complexa e indireta. Está associada com o aumento de instrumentos de análises psicométricas, testes de uso de drogas e, até mesmo, testes genéticos, que aumentam a capacidade do "olhar" para verificar, a priori, quão bem-ajustado um funcionário viria a ser, ou, qual é 
o nível de comprometimento com determinada ação ou projeto organizacional (SEWELL, 2012).

Essas práticas permeiam toda sorte de organizações e profissões, partindo de ambientes em que as tarefas são executadas de forma mecânica, como linhas de produção em fábricas, para atividades com uso de capacidades intelectuais como as universidades. Clarke e Knights (2015) demonstram como professores de Ensino Superior no Reino Unido estão submetidos a tecnologias de poder e determinação do sujeito e, simultaneamente, são objetos do olhar organizacional mediante julgamentos normalizadores, observação e exames hierárquicos. Outros estudos empíricos também reforçam esse entendimento quanto ao alcance e à ampliação desses mecanismos para uma ampla esfera de atividades (LABATUT et al., 2012; URETA, 2013). Neste estudo, o foco está voltado para o trabalho docente em IES privadas, tema debatido a seguir.

\section{O TRABALHO DOCENTE EM IES PRIVADAS}

Com a nova Lei de Diretrizes e Bases da Educação (LDB n ${ }^{\circ}$. 9.394, de 1996) e a edição do Decreto 2306, de 19 de agosto de 1997, foi permitida a existência de IES privadas com fins lucrativos no Ensino Superior do Brasil. Essa transformação precipitou a adoção de modelos de gestão de empresas que até então não pertenciam a esse segmento de atividade (SAMPAIO, 2011).

Como reflexo dessas transformações, impera nas IES privadas a necessidade constante de redução de custos, que se manifestam na constante demissão e rotatividade de professores e funcionários, redução do número de alunos e consequente reunião de turmas. Assim como o deslocamento de estudantes para novas instalações, em campi diferentes, e evasão e inadimplência de mensalidades. A constante competição para atrair e manter estudantes entre as IES privadas, também, é recorrente, nesse mercado educacional (SAMPAIO, 2011).

Atualmente, segundo o último Censo da Educação Superior (TEIXEIRA, 2017), atualizado em 31 de agosto de 2017, a educação superior no Brasil é hoje composta por $87,7 \%$ de IES privadas, sendo constituída por 
2.111 estabelecimentos, com a oferta de aproximadamente 9,9 milhões de vagas e em torno de 922 mil graduados. O total de docentes na área privada é de 214.550 , o que representa $55,9 \%$ do total de docentes no Ensino Superior do Brasil. A região Sul do país, onde foi realizada esta pesquisa, apresenta um total de 74.723 docentes, sendo 30.934 de IES públicas e 43.789 de IES privadas. Nota-se um claro descompasso entre a razão de graduados e o número de professores nas IES públicas e privadas. Enquanto o número de docentes em IES privadas representa pouco mais da metade do total de docentes no Ensino Superior (55,9\%), o número de graduados em IES privadas representa $78,9 \%$ do total. Desse modo, menos professores, nas IES privadas, formam mais alunos devido a uma lógica de máximo aproveitamento da mão de obra docente e maximização do lucro por aluno nas IES privadas.

Os professores atuantes nessa lógica são premiados e punidos principalmente em razão de pesquisa de satisfação entre os alunos pelas aulas ministradas. Os critérios dessas avaliações são na maioria subjetivos e assemelhados a pesquisas de satisfação de clientes. Há então uma inversão da lógica do ensino e da aprendizagem pela lógica do consumo e satisfação. Como consequência, tem-se que, muitas vezes, fica estabelecido o que se chama de "pactos da mediocridade" - em que o professor finge que ensina e o aluno finge que aprende (ALCADIPANI, 2011).

Como resultado dessa instabilidade do exercício da profissão de professor, um trabalho e um espaço, em que tradicionalmente se exerce a crítica e a reflexão, são substituídos por outro em que a crítica deve tornar-se sugestão "construtiva". O questionamento passa a ser visto apenas como reclamação e perguntas inoportunas com relação às práticas, que se estabelecem nas IES privadas. Aqueles que tentam de alguma forma exercer o pensamento crítico são estigmatizados em favor daqueles que se calam e adotam o consenso favorecido pela direção e pela lógica capitalista de busca do lucro num espaço até pouco tempo livre dessa influência (ALCADIPANI, 2011). A partir dos elementos conceituais da pesquisa, aqui apresentados, foi possível conduzir a pesquisa, conforme os procedimentos metodológicos detalhados a seguir. 


\section{PROCEDIMENTOS METODOLÓGICOS}

Esta pesquisa seguiu a abordagem qualitativa. Qualitativa no sentido de localizar o pesquisador numa dada situação no mundo (DENZIN; LINCOLN, 2008). Especificamente, em como as coisas funcionam na perspectiva, nas palavras e nas interpretações e significações das pessoas envolvidas no fenômeno estudado (STAKE, 2010).

Esse delineamento é o de uma pesquisa qualitativa, no sentido de descrever e explorar (GEERTZ, 1973; MARTINS; THEÓPHILO, 2009; CRESWELL, 2010) qualitativamente o fenômeno do poder disciplinar em face dos elementos da cultura organizacional em IES privadas no contexto da educação superior privada no Brasil. Verificando como são interpretadas e moldadas as relações de trabalho de professores e IES privadas por questões culturais que se expressam por meio de regras, normas, controle e vigilância. A perspectiva temporal desta pesquisa foi de corte transversal, ou seja, os dados foram coletados em certo tempo. Entretanto foi, também, uma perspectiva com aproximação longitudinal, pois os fatos de pesquisa foram considerados em uma dimensão histórica, de construção social ao longo do tempo. A pesquisa não se ateve apenas a constatação de como o fenômeno ocorreu no instante da pesquisa, mas de como ele se constituiu na perspectiva interpretativa dos participantes (NEUMAN, 2009).

Foi, então, realizada mediante um estudo de caso múltiplo, sendo o nível de análise multinível entre os sujeitos, organização e contexto (STAKE, 1995; CRESWELL, 2010). Nesse sentido, levantou-se a questão de quais IES privadas poderiam fornecer melhores respostas com relação ao controle, à normalização e vigilância de professores. Seguindo a orientação quanto aos passos na direção da seleção dos casos (CRESWELL, 2010), a resposta a esse quesito ocorreu por meio da busca de informações no sindicato local dos professores de Ensino Superior. O número de reclamações de uma IES privada no sindicato foi considerado como um indicativo ou uma evidência de que, nessas instituições, a vigilância, o controle, as normas e punições seriam mais intensos ou mais expressivos do que naquelas 
em que as reclamações fossem menores. Essas reclamações, também, encontram respaldo na avaliação do sindicato de que as IES privadas, com maior número de queixas, são as que exercem uma vigilância e controles maiores sobre os docentes e suas atividades. Inicialmente, foram três as IES privadas, situadas na região Sul do país, que compuseram o estudo de caso múltiplo.

Das IES privadas estudadas, duas são classificadas como centros universitários e uma, como universidade. A diferença entre uma classificação e outra está basicamente em dois itens. (1) O centro universitário deve possuir um quinto dos seus professores em regime de contrato em tempo integral, enquanto a universidade deve possuir um terço em contrato de tempo integral. (2) Para a IES ser classificada como universidade, é necessário, ainda, que possua ao menos quatro programas de pós-graduação strictu sensu, sendo um deles um programa de doutorado. Como característica comum, é exigido que tanto o centro universitário quanto a universidade possuam um terço do corpo docente com titulação de mestrado ou doutorado.

A fim de não identificar as organizações objetos do estudo, basta registrar, sem a precisão exata das dimensões de cada IES, que todas elas possuem mais de três mil alunos em cursos de graduação presenciais e mais de cem docentes atuando em seus quadros. São IES com mais de dez anos de atuação no mercado de Ensino Superior privado e foram selecionadas pelo critério estabelecido na metodologia, que foi o indicado pela direção sindical quanto a serem instituições que são percebidas como as que mais exercem controles disciplinares sobre os docentes.

Vencida a questão de quais IES privadas comporiam o estudo, passou-se à reflexão de como seriam selecionados os sujeitos participantes do fenômeno em estudo dentro dessas organizações. As relações sociais determinadas pelo poder disciplinar, em um contexto de cultura organizacional de uma IES privada, envolvem o próprio docente como sujeito de toda uma série de práticas disciplinares, e os dirigentes ou seus representantes (como coordenadores e diretores) da organização como produtores e reprodutores dessas mesmas práticas. 
Dessa forma, o critério de seleção dos sujeitos da pesquisa foi realizado da seguinte forma: três sujeitos de cada uma das IES privadas selecionadas para o estudo; sendo um docente com vínculo ou alguma forma de relação junto ao sindicato; um coordenador ou diretor de curso da IES privada; e um professor sem vínculo sindical do quadro da IES privada. Assim, foram nove o total de sujeitos selecionados para a realização desta pesquisa. Dos docentes entrevistados, um apresentava nível de especialista, cinco, a titulação de mestre, um, de mestre e fazendo o programa de doutorado, e dois, doutores. As áreas de atuação nos cursos de graduação eram das áreas de: sociais aplicadas, em especial, administração; humanas; biológicas; e comunicação social.

As IES privadas pesquisadas foram categorizadas como IES1, IES2 e IES3. Sendo que os sujeitos da pesquisa foram classificados em IES1A, IES2A e IES3A para aqueles que exercem algum cargo de direção (coordenação de curso, diretor de curso ou de ensino e pró-reitores) na organização. IES1B, IES2B e IES3B para aqueles que são os representantes sindicais dentro da instituição. E, IES1C, IES2C e IES3C para aquele grupo de professores que não pertence nem à direção nem ao sindicato.

Os sujeitos da pesquisa deveriam possuir ao menos cinco anos de experiência na docência do Ensino Superior em instituições privadas. No decorrer da pesquisa, verificou-se que a maioria dos docentes já havia lecionado em diversas outras IES privadas: em IES privadas menores e até mesmo entre as IES deste estudo. Além disso, observou-se que vários deles passaram em algum momento da carreira pela experiência de coordenação de curso. Além dessa caracterização dos sujeitos e casos, foi adotado como critério, a fim de manter o anonimato tanto dos sujeitos quanto das IES privadas, alterações pontuais nas transcrições das falas dos sujeitos e transcrições dos materiais secundários reproduzidos na análise. Essas alterações não mudam de forma alguma o sentido originário do texto. Trata-se de substituições dos nomes dos cursos, por graduação, ou do nome das IES, por outras referências.

Com relação aos dados documentais, esses se dividem em documentos públicos e documentos privados. Os documentos públicos foram obti- 
dos por meio das páginas das IES privadas, que visam, fundamentalmente, estabelecer, de um lado, o contexto da cultura organizacional esposada em termos de valores e moral, e, de outro, identificar normas, regras, regulamentos com relação aos docentes e à atividade docente. Também, foram coletados documentos do sindicato como reclamações, processos ajuizados contra as IES privadas e publicações como o jornal sindical. Os documentos privados foram aqueles fornecidos pelos sujeitos da pesquisa, como contratos de trabalho, e-mails, notificações, etc.

Para a realização desta análise qualitativa dos dados, o método empregado foi o da análise do discurso organizacional. Esse método não possui uma única forma de realização, pelo contrário, a diversidade de formas e tipos é de tal maneira variada em termos de epistemologias e metodologias que são frequentes os estudos e debates em publicações nacionais e internacionais (ALVESSON; KARREMAN, 2011a; 2011b; 2013; MUMBY, 2011; HARDY; GRANT, 2012; HARDY; PHILLIPS, 2004; FARIA, 2015).

O modelo de análise de discurso organizacional está dividido basicamente em dois campos que se relacionam mutuamente: o campo do discurso e o campo da ação. O campo do discurso (Figura 1) analisa como o discurso produz relações de poder e irá constituir o contexto social em que a ação irá se desenrolar. O discurso aqui é compreendido como conjuntos estruturados de textos e práticas de produção, consumo e transmissão desses textos em um contexto social e histórico. Os textos não se limitam aos escritos e transcritos verbais, mas a toda uma gama de expressões simbólicas que assumem uma mídia física na forma de, entre outros, artefatos culturais, representações visuais, construções, arquitetura de espaços, roupas, etc. O discurso, ao associar conceitos, objetos e posições dos sujeitos a certos significados, estabelece relações de poder que, embora mudem ao longo do tempo, em determinado momento, são efetivamente fixadas (HARDY; PHILLIPS, 2004; LECLERCQ-VANDELANNOITTE, 2011). 
Figura 1 A relação entre discurso e poder.

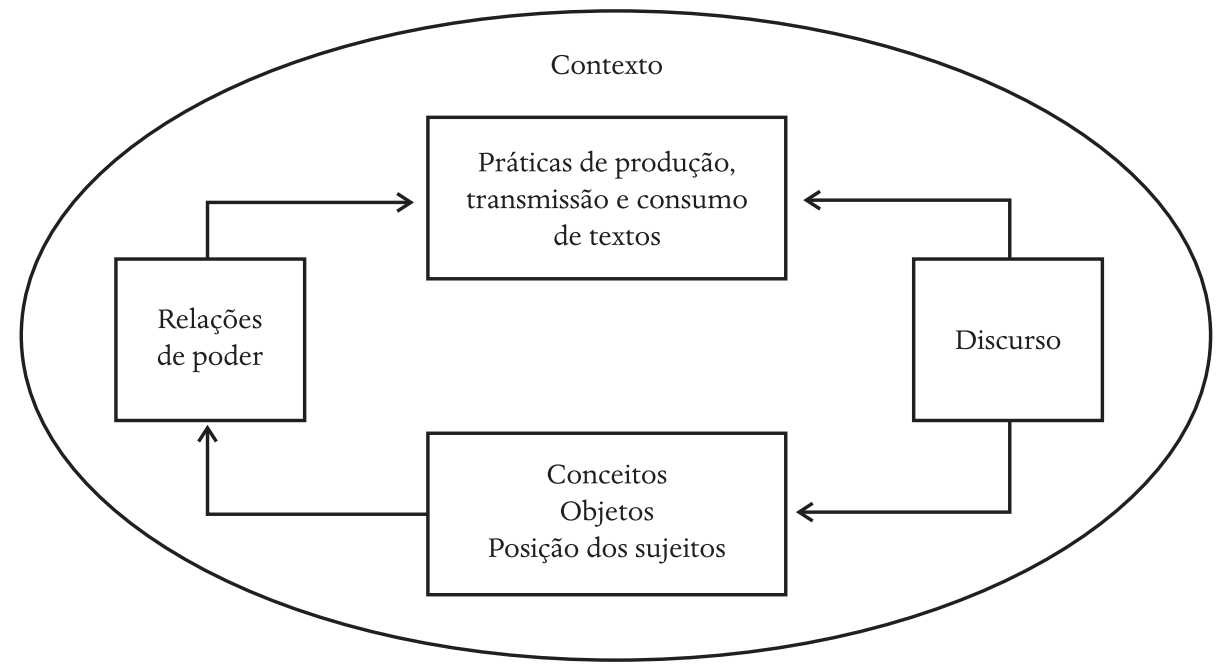

Fonte: Elaborado pelo autor com base em Hardy e Phillips (2004).

Os sujeitos agem, então, por meio de táticas, propositais ou não, na produção, na transmissão e no consumo de textos baseados em discursos (estratégias) existentes. A produção e o consumo (interpretação) desses textos são limitados e moldados pelos discursos dominantes. É nesse sentido que o discurso irá estruturar o espaço social das ações táticas dos sujeitos. Ao estabelecer significados particulares no conjunto de conceitos, objetos e posições dos sujeitos, o discurso influencia as relações de poder no sentido de quem pode e quem o exerce. Nesse espaço, em que os sujeitos exercem suas táticas e relações de poder, é que as potenciais mudanças do discurso podem ocorrer ao longo do tempo. No campo do discurso, a sua influência nas relações de poder foi examinada em um momento determinado (HARDY; PHILLIPS, 2004; LECLERCQ-VANDELANNOITTE, 2011).

No campo da ação (Figura 2) são as relações de poder que irão influenciar o discurso. Essa influência é revelada ao longo do tempo, ou seja, na análise do que Foucault (1995) afirma ser não a história do passado, mas a intenção do presente daquele passado. No âmbito da ação, as práticas de 
produção, transmissão e consumo adicionam novos textos que poderão acarretar mudanças nos conceitos, objetos e posições dos sujeitos que irão implicar mudanças no discurso ao longo do tempo (HARDY; PHILLIPS, 2004).

Figura 2 A relação entre poder e discurso.

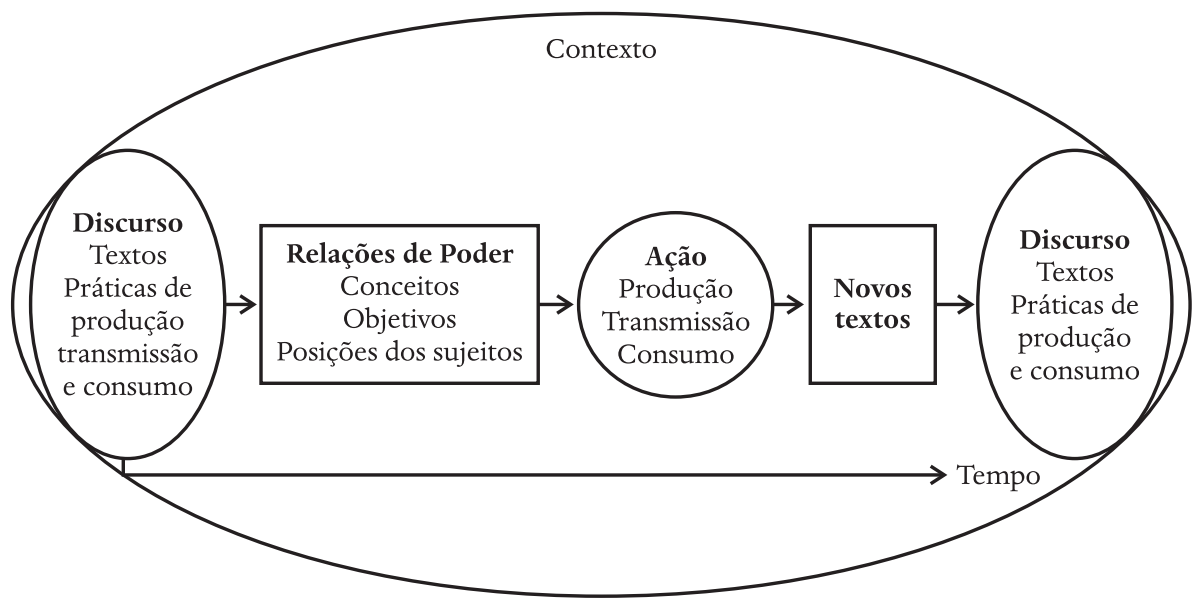

Fonte: Elaborado pelo autor com base em Hardy e Phillips (2004).

A produção e transmissão de textos requerem dos sujeitos determinada capacidade no desempenho dessas práticas. A produção e transmissão não são limitadas apenas em disputas de poder sobre os significados dos textos. Para ser capaz de influenciar o discurso, por novos textos, a posição dos sujeitos deve ser analisada em associação ao poder formal que esse sujeito ocupa no quadro das relações sociais da organização. Ainda, no acesso a recursos disponíveis ao sujeito, nas redes de relacionamentos e associações que o sujeito estabelece, bem como na legitimidade que o sujeito possui em relação ao discurso, ou seja, no direito à voz dada ao sujeito em se pronunciar no tocante à realidade da organização (CLEGG, 1989; HARDY; PHILLIPS, 2004). A relação de mutualidade entre o campo do discurso e o campo da ação se mostra nos limites da capacidade da posição desse sujeito dentro do discurso. Sua subjetividade e sua identidade é ela própria, em 
parte, construída dentro desse discurso da organização (LECLERCQ-VANDELANNOITTE, 2011).

A linguagem, como preconiza Foucault (1999b), não é apenas um sistema de representações com o poder de destrinchar e reconstituir outras representações, mas sim um sistema de linguagem em que a realidade é estabelecida, em suas raízes, pelas ações, pelos estados dos sujeitos, e, fundamentalmente, pelas vontades desses sujeitos. A linguagem é, então, um meio de poder e de controle social (FOUCAULT, 1999a, 1999b). Assim, apresentam-se na sequência os resultados obtidos e as análises efetuadas, considerando os objetivos deste estudo. 


\section{ANÁLISE E DISCUSSÃO DOS RESULTADOS}

Ao tratar alguns elementos da cultura organizacional como uma forma de manifestação do poder disciplinar, realizada em forma de construções discursivas, não se deixou de abordar questões específicas de cada IES. Entretanto foram destacados aqueles elementos que, de certa forma, são comuns a todas elas e que irão, além do espaço e tempo circunscrito pela IES, permear a carreira docente no setor privado.

O primeiro aspecto a ser analisado foi o contato do sujeito com a cultura organizacional da IES, e com a carreira docente nesse ambiente. Esse contato, de certa forma, já implica em mecanismos próprios do poder disciplinar, como a vigilância hierárquica; a sanção normalizadora; e o exame na forma definida nessa pesquisa (FOUCAULT, 2004). Na sequência, foram abordados os aspectos do exercício da profissão de professor nessas IES privadas, dos elementos da cultura organizacional que são articulados pela linguagem, textualidade, representação, discurso e do simbólico formando um senso de direção para os indivíduos do que é certo ou errado (FREITAS, 2000).

Esse poder disciplinar, conforme aqui se demonstra, não é apenas aquele exercido pela direção da IES privada, mas sim aquele adquirido em meio à cultura organizacional e que, embora não aparente e opressor, serve a interesses específicos presentes na produção, na transmissão e no consumo de textos desse discurso do Ensino Superior privado (ENGELSTAD, 2009). Por fim, a análise irá tratar das expectativas dos sujeitos com relação ao futuro da sua carreira, ao futuro do Ensino Superior no âmbito das IES privadas. De como os textos representativos dos elementos da cultura organizacional, em forma de mecanismos do poder disciplinar, são produzidos, transmitidos, consumidos e resistidos no que esperam tornar o discurso futuro do Ensino Superior nas IES privadas. 


\section{AS MANIFESTAÇÕES DO PODER DISCIPLINAR NA CULTURA}

ORGANIZACIONAL NA INICIAÇÃO AO ENSINO SUPERIOR PRIVADO

A maior parte dos sujeitos desta pesquisa teve contato com a docência no Ensino Superior já na sua formação. Quando da realização da formação em nível de mestrado e doutorado, os sujeitos já participaram de atividades de docência como estágio ou de outras formas de monitoria e mesmo substituição de professores em IES privadas menores. Também, é nesse momento que os sujeitos tomam contato com os valores e as crenças acerca da profissão de docente do Ensino Superior. Nesses valores e crenças, incluem-se aquela visão do professor acadêmico como detentor da autonomia de ensino e pesquisa. Daquele atributo referido anteriormente como a liberdade de cátedra, em que o professor de Ensino Superior exerce o ensino e a pesquisa em relativa liberdade de pensamento e ação. Esse é mesmo um atributo da cultura da carreira que, na interpretação dos sujeitos, exerce influência considerável na escolha da docência como profissão.

A ação do poder disciplinar sobre os elementos culturais manifesta-se nessa fase em sua forma indireta, ou seja, mediante a persuasão e o convencimento sobre um conhecimento e conjunto de crenças dos sujeitos em relação ao Ensino Superior privado e da concepção de como esse ensino deva ser em termos de normas, valores, preferências pessoais e lealdades políticas (ENGELSTAD, 2009).

Nesse percurso, a experiência profissional, ou experiência de mercado como relatada, é considerada um fator de diferenciação entre IES públicas e privadas na interpretação dos docentes que participaram deste estudo. Essa diferenciação deve-se ao fato de que as próprias IES propagam em seus textos oficiais e promocionais uma sintonia com o mercado na busca de atrair o aluno cliente. A cultura organizacional é, então, um campo de disputa cuja visão dominante das IES privadas é apoiada por meio de histórias, reivindicações e discursos; e isso com o intuito de fazer essa vinculação com o mercado ser a visão dominante desse espaço e suplantar posições e discursos diferentes, como os puramente acadêmicos (HATCH; CUNLIFFE, 2006). Essa diferenciação reflete-se já no processo de seleção de docentes: 
Networking é essencial para você... é claro que sim estamos falando de universidades privadas... é claro que você tem que ter também a formação... Então você tem que ter uma desenvoltura, ter um domínio do conhecimento para o qual você está sendo avaliado. Você está sendo avaliado! Acho que tem outra coisa que também conta, que no meu caso aqui na IES contou bastante também, era a minha experiência de mercado, ter trabalhado, ter feito as coisas na prática. Lá eu sei que contou muito. Se fosse fazer numa instituição pública valeriam os pontinhos no currículo, se você tivesse tudo explicadinho dizendo que você fez trabalho naquele lugar, as Produções técnicas no Lattes, mas lá tem um peso muito maior. O mercado, ter trabalhado. Então na verdade eu acredito que para você ser professor em instituições privadas: indicação; conhecimento do mercado, experiência de mercado. Você tem que ter as duas coisas e, é claro que a desenvoltura e o domínio do conhecimento, nesse sentido que você vai competir. (ENTREVISTADO IES2C).

Essas relações entre normas, exigências, práticas e discursos que permeiam as IES e a carreira acadêmica são apresentadas reiteradamente e acabam por serem internalizadas pelo sujeito sem a consciência de seu propósito original. Apenas seu efeito final é aparente (CALAS; SMIRCICH, 1999).

A crença principal, percebida pelos sujeitos da pesquisa, é a de que a profissão de professor em uma IES privada não é propriamente uma carreira, e, sim, uma atividade temporária, em razão de muitos professores terem contrato de horistas. Esse contrato, o de professor-horista, transforma o trabalho docente em um trabalho "precário", na palavra de alguns dos entrevistados. Porém alguns também reconhecem que há professores que conseguiram atingir boas posições dentro das IES privadas, em posições melhores nos planos de cargos e salários. Todavia, claramente, percebem que isso só é possível para uma pequena minoria, e que a maioria se encontra em uma situação precária e instável:

Esse mercado é extremamente corroído, e na verdade há uma alta rotatividade, então não há atrativo por causa desses dois elementos: alta 
rotatividade, e, a corrosão salarial. Então, na verdade se transformou num bico dar aula em instituição privada. (ENTREVISTADO IES2B).

Mas por outro lado tem muito professor que continua sendo horista (...). No sistema atual de faculdade, com pouco espaço para produção e disseminação do conhecimento, sem outros mecanismos, sem pesquisa inovadora para indústria, sem consultoria como uma espécie de extensão, sem outras atividades para o professor, não se financia além do professor horista, e a maioria fez essa escolha. Mesmo as grandes que são universidades estão indo para essa direção, ou ao menos mantendo segmentos separados de professores, para alguns professores com dedicação exclusiva e muitos horistas. Por isso então eu vejo sem muita expectativa de melhora nesse modelo. (ENTERVISTADO IES3B).

Essa crença de que a carreira de professor em uma IES privada é apenas uma atividade temporária, sem perspectiva de desenvolvimento ao longo da vida profissional, é produzida em forma de discurso, com fundamento, na experiência de todos os sujeitos entrevistados, frente às frequentes substituições, demissões e alta rotatividade de professores nas IES privadas.

Conforme estabelecido anteriormente, a influência do poder público sobre as IES privadas é preponderante em termos de alterar seu modo de funcionamento, e, as relações entre direção, professores e alunos. Em particular, tem-se que é demandado das IES privadas a existência de um plano de carreira para os docentes. Esse plano de carreira docente seria uma forma de assegurar a clareza e uniformidade de contratos de trabalho e a perspectiva de desenvolvimento e capacitação dos professores ao longo da sua vida funcional. No entanto as IES privadas utilizam-se desse plano como uma ferramenta para a substituição e diminuição de custos com o salário dos professores.

$\mathrm{O}$ discurso das IES em relação à cultura do Ensino Superior privado é composto por novos termos até então estranhos ao meio acadêmico: a produtividade, o trabalho em equipe com a coordenação, a qualidade do trabalho medida em termos de seguir um programa, e, um planejamento já 
estabelecido, a aderência a esse programa e a um perfil de egresso desejado; constituem em esforços do corpo diretivo das IES em alistar os professores para cooperar, comprometer-se e conformar-se.

O poder disciplinar está, em determinados momentos, como um discurso fixado com seus próprios objetos, conceitos e posições dos sujeitos. Aquela situação é percebida pelo recém-chegado como pronta, como uma situação dada em que ele não possui outra capacidade que não a de se submeter. O sujeito/corpo manifesta os efeitos desse discurso regulador da cultura organizacional nos seus hábitos, gestos, postura, fala e na expressão dos sentimentos (FREITAS, 2000; CHAN; CLEGG, 2002).

O professor iniciante nas IES pesquisadas depara-se com uma situação em que é contratado por um salário inferior, em termos de valor de hora-aula. Mas precisa do trabalho para iniciar a carreira docente ou incrementar sua carreira profissional. Os professores relatam que lecionam disciplinas nas quais não possuem nenhuma influência sobre o conteúdo, que já foi previamente determinado sem a sua participação. A forma que a aula será ministrada ou o modo aceito pela IES, de como o ensino será realizado, foi também determinado pelos cursos de ambientação. Em alguns casos, a própria avaliação que o professor irá aplicar aos alunos deve ser previamente submetida à coordenação para que sejam avaliados os conteúdos que serão cobrados dos alunos. Por pior que pareça essa situação, não é percebida como sendo ruim no momento da admissão. Uma entrevistada descreveu a sua experiência e reflexão, feita anos depois, sobre o início de seu trabalho na IES:

Confesso que no começo fiquei encantada com a estrutura, encantadíssima. (...) É engraçado porque eu, e, uma outra professora que entramos, nós estávamos muito encantadas, e quem estava lá não estava encantado e a gente meio que destoava... E, agora eu acho que é a gente que foi para o lado dos outros, sabe? Daí você começa a entender e a ver o funcionamento, enfim, mas foi bem interessante, a estrutura ainda é boa..., mas, está cada vez mais com a visão de mercado. (ENTREVISTADA IES1C). 
O que se observa da realidade desse contexto é que as relações de poder são alteradas ao longo do tempo, por meio, das ações de produção, transmissão e consumo de novos textos. Essas alterações irão influenciar o discurso, que poderá ser mantido ou alterado acarretando ou não mudanças nos conceitos, nos objetos e nas posições dos sujeitos (HARDY; PHILLIPS, 2004). A partir dessa entrada, em que vários mecanismos de controle e ajuste do sujeito à ordem do discurso estabelecido pela cultura organizacional, tem-se a realização do principal rito do ensino e, consequentemente, da IES privadas, a aula. É na sala de aula que tanto professores novos quanto professores experientes são submetidos a toda forma de vigilância e que o controle sobre o seu desempenho é minuciosamente exercido. Como será descrito a seguir.

\section{AS MANIFESTAÇÕES DO PODER DISCIPLINAR NA CULTURA ORGANIZACIONAL: VIGILÂNCIA, EXAME E PUNIÇÃO NO CONTEXTO DAS IES PRIVADAS}

Uma IES privada, enquanto instituição disciplinar, tem de assegurar sua existência fundamentalmente por meio de práticas de vigilância e controle como elementos de normalização (FOUCAULT, 1998, 1999a, 1999b, 2002, 2004, 2008a, 2008b).

Como já mencionado, o poder disciplinar tem como objeto o corpo, a administração dos corpos para o objetivo de aumentar suas capacidades produtivas, ao mesmo tempo que reduz sua capacidade política. Na sala de aula, todos os requisitos para seu exercício estão à disposição. A distribuição dos sujeitos no espaço, o controle do horário para garantir a utilização máxima do tempo e o desmembramento das ações no controle temporal do ato, ou seja, desmembramento da ação em etapas, num encadeamento lógico dos movimentos e das atividades em um programa de ensino, num programa de disciplina com todos os conteúdos dispostos numa sequência de aulas previamente estabelecida (FOUCAULT, 2004).

A vigilância nas IES privadas está ligada, como nas demais organizações, à capacidade da administração em monitorar, registrar e acompanhar o desempenho, o comportamento e as características dos professores para 
controlar a ascensão na hierarquia e o próprio acesso ou a permanência na organização (BALL, 2010). A vigilância possui o propósito de averiguar se as obrigações do contrato de trabalho estão sendo cumpridas de acordo com o desejado pela direção, e são aplicadas nesse espaço e tempo das IES privadas e nas suas adjacências.

Os dirigentes das IES privadas, seus prepostos e até mesmo os alunos como clientes são, nesse contexto, os agentes da vigilância. Aqueles que empregam os instrumentos e detêm o conhecimento e, consequentemente, a primeira posição no desenho de poder da relação. Os professores passam a ser os sujeitos da vigilância, que são aqueles submetidos à coleta de informações, e, na medida em que tomam consciência do controle a que estão submetidos, agem ou não no sentido de resistência e tentativa de minimizar sua sujeição e situação na relação de poder (MARX, 2012; 2015).

Uma vez presente na IES privada e dentro da sala de aula, o professor será submetido a uma rigorosa vigilância. A vigilância simples e direta sobre os olhares dos alunos. O exercício dessa vigilância ocorre principalmente de duas maneiras. A primeira delas a partir da cobrança de demandas diversas diretamente em sala de aula. A segunda na forma de reclamações na coordenação ou na avaliação discente, aspectos observados na pesquisa e também mencionados no trabalho de Sewell (2012).

O professor, ao adentrar pela sala, é vigiado, comparado e examinado pelos alunos individual e coletivamente. Suas roupas, sua aparência, sua conduta e toda sua forma de apresentação pessoal e profissional são esmiuçadamente avaliadas. A relação estabelecida com os alunos também é constantemente vigiada e avaliada. A classificação ou categorização dos professores, resultante do exercício do poder disciplinar, faz com que os desvios sejam marcados, as qualidades, as competências e aptidões hierarquizadas e ordenadas operando recompensas e promoções ou rebaixamento e degredos (FOUCAULT, 2004). Obviamente não se pode aqui esgotar todas as formas de como essa relação é criada e mantida ao longo de um semestre letivo, na duração de uma ou mais disciplinas e nos diferentes cursos de disciplinas e suas especificidades. 
Quando se estabeleceu que um dos propósitos da vigilância do trabalho é assegurar o cumprimento do contrato por parte do empregador pode ser observado aqui que esse contratador em última instância na IES privada é o próprio aluno. Um professor que recebe muitas e frequentes reclamações, dificilmente permanece, mais que dois semestres, em uma IES privada. A avaliação discente não é o único instrumento. Nas IES privadas deste estudo, ela é o principal componente, que é somado ainda a uma avaliação realizada pelo coordenador e consolidada em uma classificação final.

O professor também deve manter atualizado seu plano de aulas nos portais acadêmicos. A centralidade desse instrumento assegura mais controle por parte das IES sobre a atividade dos professores do que a de alunos. Qualquer alteração de notas, presenças ou modificações dos planos de aulas podem ser monitoradas pelas IES. Inclusive, o tempo dedicado ao portal pode ser monitorado. A IES passa a ter um controle direto sobre o processo de ensino em que o professor é um mero executor nesse projeto educacional. E, para ser bem-avaliado, deve agradar o cliente da IES. Agradar o cliente aqui significa não ser exigente demais na cobrança dos conteúdos da disciplina e possibilitar que, com um esforço mínimo, o aluno possa ser aprovado. O professor que cobra o conteúdo, que produz uma resistência ao andamento desse ensino palatável ao cliente, certamente, terá sua carreira interrompida em uma IES privada. O caso mesmo de progredir no plano de carreira docente depende inteiramente disso, como mostra o seguinte depoimento:

E, a estabilidade ela depende na maioria das vezes de agradar as turmas, por exemplo, eu tenho vários relatos de professores que cobraram a matéria, curso por exemplo de engenharia e outros cursos, reprovaram os alunos que foram demitidos sumariamente... não ser exigente e não cobrar, e se fizer isso há uma fuga dos alunos. Que os alunos também estão submetidos a esse tipo de sistema, quer dizer eles estudam o mínimo assistem às aulas, marcam um $\mathrm{X}$ nas provas e são aprovados, num processo automático de aprovação. As reprovações são raríssimas... O aluno se agiganta porque as instituições fazem com que o aluno... O aluno consumidor... questão do horário, questão do controle do ponto, questão do controle do livro a ser 
preenchido ou não, várias coisinhas que vão minando a liberdade acadêmica do professor, várias coisinhas que vão fazendo com que ele, o professor, seja um mero instrumento nessa engrenagem. (ENTREVISTADO IES2B).

O professor é visto como um mero executor dessa sistemática de ensino adotada nas IES privadas. O poder disciplinar articulado em um conjunto de textos e práticas discursivas e elementos culturais como normas, procedimentos, hábitos amolda a ação e, nas palavras de Foucault (2004), o gesto do sujeito ao trabalho na forma dos resultados desejados pela organização. Nesse sentido, o gesto, como expressão mínima da ação, está inserido numa lógica global de controle. Sendo que este corpo disciplinado constitui a base e o resultado de um gesto eficiente (FOUCAULT, 2004). Mesmo discordando, ou não gostando, o professor acaba se submetendo à condição imposta pela organização para poder trabalhar. Trabalhar não com liberdade de cátedra ou liberdade de ensino, mas como um mero operário devidamente controlado dessa indústria do Ensino Superior.

Esse movimento, das IES privadas em direção a um modelo de negócio, não passa despercebido pelos professores. E, mesmo como um invólucro cultural, ajusta as ações desses profissionais como docentes e coordenadores no desempenhar diário de suas atividades. Todos esses esforços são empreendidos no sentido de demonstrar a dimensão da influência desse poder na vida dos sujeitos, que partem de pequenas práticas e técnicas arraigadas na rotina diária, nos pequenos discursos de verdade, conhecimento e autoridade (CLEGG; BAUMELER, 2010). O instrumento da avaliação e da classificação é a materialidade desse discurso e o produto e reprodutor das ações do poder disciplinar. Ao criar avaliações, os produtores desse discurso, na posição de dirigentes das IES privadas, esperam ajustar o campo das ações dos professores para que ajam da forma que esperam. Contudo esse discurso não é consumido de modo irrefletido e sem resistência por todos. Alguns professores não têm consciência ao que estão sujeitos, outros têm o conhecimento e a reflexão sobre isso, e atuam da forma que se espera deles, de forma refletida, e há aqueles que resistem a essa lógica de avaliação. O relato de um professor ilustra esse aspecto: 
E, também exigem o aperfeiçoamento constante do professor então nós temos que cumprir uma carga horária anual de cursos que nós temos que participar. De cursos internos, internos basicamente podem ser externos, mas eles oferecem os cursos então nós temos os cursos em $\mathrm{EaD}$ e presenciais, e é obrigatório fazer esses cursos. Vamos dizer assim, não é que seja obrigatório, mas é um obrigatório entre aspas. Se você não fizer cai no rankeamento dos professores. Você cai. (ENTREVISTADO IES1A).

Além de classificar os sujeitos nesse novo sistema disciplinar e punitivo, as alterações nas relações sociais passam a ser pautadas por um conjunto diferente de valores e crenças. A abertura de informações e o tratamento de pares, comuns ao Ensino Superior até então, passam a ser modificados para relações hierárquicas de negócios, em que as posições superiores detêm informações e a capacidade de avaliar comportamentos e distribuir punições. O professor passa a ser vigiado como um funcionário, e o governo das suas ações passa a ser o determinado pelo discurso dominante da IES privada.

A punição no poder disciplinar realiza, então, as seguintes operações: relaciona os atos, desempenhos e comportamentos em um conjunto comparável, diferençável e conforme a regra; aplica essa diferenciação aos indivíduos comparativamente uns aos outros, tendo por base um mínimo nível aceitável ou nível ótimo a realizar; mensurar quantitativamente hierarquizando as capacidades, os níveis e a natureza dos indivíduos; coagir para a conformidade aos valores e níveis que devem ser realizados; e estabelecer o limite entre todas as diferenças, ou seja, o que é normal do anormal. O poder da norma claramente coaduna com um sistema de organização formal, pois, ao mesmo tempo que aplica a normalidade geral da regra, possibilita a mensuração individualizada de conformidade ou não em relação a ela (FOUCAULT, 2004). 


\section{CONSIDERAÇÕES FINAIS}

A ação do poder disciplinar sobre os elementos culturais manifestou-se, nas IES pesquisadas, por meio de mecanismos de vigilância, exame e punição, capazes de persuadir e convencer, de produzir conformidade, mas, também, resistência. Atua, dessa forma, sobre o conhecimento e o conjunto de crenças dos sujeitos em relação ao Ensino Superior privado e da concepção de como esse ensino deve ser em termos de normas, regras, valores e formas de atuação.

Com destaque para o claro movimento dos dispositivos já incorporados na cultura organizacional, qual seja, os sistemas de vigilância, a avaliação e a punição nas IES deste estudo. Nessas, o professor passa a ser vigiado como um funcionário, e o governo das suas ações passa a ser determinado pelo discurso dominante da IES privada. Quanto à avaliação, à abertura de informações e ao tratamento de pares comuns ao Ensino Superior até então, esses aspectos passam a ser modificados para relações hierárquicas de negócios em que as posições superiores detêm informações e a capacidade de avaliar comportamentos e distribuir punições. Os docentes, em uma lógica invertida, é que passam a ser duramente avaliados e examinados pelo corpo discente, segundo as diretrizes das IES, pela ótica do aluno cliente.

A punição, no âmbito do poder disciplinar, não visa compensações em relação à transgressão da norma. A punição visa ao ajustamento à norma. No caso da IES privada, o objetivo é o professor normalizado a essa nova lógica de negócio de "Ensino Superior". O professor que satisfaça o aluno cliente. Esse professor normalizado, além de agradar o aluno, deve ser um constante agente indireto na promoção da IES no mercado perante suas concorrentes. Deve possuir uma atitude positiva para com a IES e deve ser, ainda, atuante no mercado da sua profissão. Questionar as diretrizes da IES privada, combater e resistir ao discurso imposto pela direção, agir de forma independente, pensar e questionar livremente a forma como o ensino ocorre numa IES privada é um fator certo para a demissão. Além de classificar os sujeitos nesse novo sistema disciplinar e punitivo, as altera- 
ções nas relações sociais passam a ser pautadas por um conjunto diferente de valores e crenças.

Nessa perspectiva, este trabalho contribui ao demonstrar como é compreendida e interpretada, pelos próprios professores, a carreira do docente no Ensino Superior privado por meio dos elementos da cultura organizacional articulados enquanto uma dimensão do poder disciplinar. Dentro desse limite, uma contribuição prática deste trabalho foi constatar como os discursos da competição, do mercado e da finalidade do lucro operam para modificar esses elementos culturais e fazer deles instrumentos disciplinares que governam as ações desses profissionais.

A relevância da educação superior privada no Brasil, já mencionada nos números de graduados e de professores, demonstra que esse segmento é de fundamental importância para o desenvolvimento do país. Desse modo, ao perceber-se a fragilidade da carreira docente e das condições de trabalho do professor, pode-se concluir que outra contribuição deste trabalho está no esclarecimento e aumento da compreensão acerca dessa realidade. Este trabalho pode contribuir para agregar informações a futuras ações sindicais, governamentais e empresariais nesse setor.

A contribuição teórica é realizada em dois momentos. No primeiro, com a ampliação da compreensão dos fenômenos da cultura na organização, como uma forma discursiva e instrumental de poder combinada com uma forma de compreender o fenômeno de poder nas organizações, com a utilização de uma analítica de poder de Foucault ampliada aos seus últimos estágios de desenvolvimento. No segundo momento, o trabalho preenche a escassa base de trabalhos empíricos que utilizam esses conceitos nos estudos organizacionais (HASSARD; ROWLINSON, 2002; SILVEIRA, 2002; BROWN et al., 2010; LECLERCQ-VANDELANNOITTE, 2011; DICK; COLLINGS, 2014; CLARKE; KNIGHTS, 2015).

Assim, ao analisar a forma como esse sistema cultural e disciplinar é vigente e reproduz-se diariamente, só é possível compreender que a sua existência permanece por se tratar de controles que não são absolutos, o poder disciplinar só submete à medida que opera por mecanismos incorporados como normais na realidade, esta pesquisa almejou, dentro de seus li- 
mites, contribuir no desafio de enfrentá-los. Assim, para lembrar Foucault: "Existem momentos na vida onde a questão de saber se se pode pensar diferentemente do que se pensa, e perceber diferentemente do que se vê, é indispensável para continuar a olhar ou refletir. [...] em vez de legitimar o que já se sabe." (FOUCAULT, 1999a, p. 13).

Nesse contexto, como sugestões para pesquisas futuras, propõe-se a realização de um estudo de caso único com uma metodologia de investigação etnográfica que poderia aprofundar, ainda mais, as questões que foram abordadas neste trabalho, como, por exemplo, o acompanhamento do ingresso de novos professores, a saída ou demissão de outros e o acompanhamento de mudanças em planos de cargos e salários em uma IES privada. Adicionalmente, uma pesquisa futura poderia ampliar a abordagem do poder disciplinar e da cultura organizacional para verificar como a vida dos docentes fora da IES privada é afetada por essas influências. 


\section{REFERÊNCIAS}

ALCADIPANI, R. Academia e a Fábrica de Sardinhas. Organizações \& Sociedade, v. 18, n. 57, p. 345-348, 2011.

ALVESSON, M. Understanding organizational culture. London: Sage publications, 2002.

ALVESSON, M.; KARREMAN, D. Decolonializing discourse: Critical reflections on organizational discourse analysis. Human Relations, v. 64, n. 9, p. 1121-1146, 2011 a.

ALVESSON, M.; KARREMAN, D. Organizational discourse analysis - well done or too rare? A reply to our critics. Human Relations, v. 64, p. 1193-1202, 2011b.

ALVESSON, M.; KARREMAN, D. The closing of critique, pluralism and reflexivity: A response to Hardy and Grant and some wider reflections. Human Relations, v. 66, n. 10, p. 1353-1371, 2013.

BALL, K. Workplace surveillance: an overview. Labor History, n.1, p. 37-41, 2010.

BALL, K.; MARGULIS, S. T. Electronic monitoring and surveillance in call centres: A framework for investigation. New Technology, Work and Employment, v. 26, n. 2, p. 113-126, 2011.

BARKER, J. R. Tightening the Iron Cage: Concertive Control in Self-Managing Teams. Administrative Science Quarterly, v. 38, n. 3, p. 408, 1993.

BARRATT, E. Foucault, HRM and the Ethos of the Critical Management Scholar. Journal of Management Studies, v. 40, n. 5, p. 1069-1087, 2003.

BASTOS, A. V. B. O ofício acadêmico: singular ou plural? Organizações \& Sociedade, v. 14, n. 43, p. $179-185,2007$.

CALAS, M. B.; SMIRCICH, L. Past postmodernism ? Reflections and tentative directions. Academy of Management Review, v. 24, n. 4, p. 649-671, 1999.

CASTRO, D. J. et al. As significações culturais sob diferentes perspectivas organizacionais: em estudo, uma organização do setor de tecnologia da informação. Administração: Ensino e Pesquisa, v. 10, n. 3, p. 105-128, 2009.

CHAN, A.; CLEGG, S. History, Culture and Organization Studies. Culture and Organization, v. 8, n. 4, p. 259-273, 2002.

CLARKE, C. A.; KNIGHTS, D. Careering through academia: Securing identities or engaging ethical subjectivities? Human Relations, v. 68, n. 12, p. 1865-1888, 2015.

CLEGG, S.; BAUMELER, C. Essai: From Iron Cages to Liquid Modernity in Organization Analysis. Organization Studies, v. 31, n. 12, p. 1713-1733, 2010.

CLEGG, S. R. Frameworks of Power. London: Sage publications, 1989.

CLEGG, S. R.; COURPASSON, D.; PHILLIPS, N. Power and Organizations. London: Sage publications, 2006. 
CLEGG, S. R.; HAUGAARD, M. Introduction: Why Power is the Central Concept of Social Sciences. In: HAUGAARD, M.; CLEGG, S.R. (Orgs.). The Sage Handbook of Power. London: Sage publications,2009. p.1-24.

CRESWELL, J. W. Projeto de pesquisa: métodos qualitativo, quantitativo e misto. 3. ed. São Paulo: Bookman, 2010.

DENZIN, N. K.; LINCOLN, Y. S. Introduction: the discipline and practice of qualitative research. In: DENZIN, N. K.; LINCOLN, Y. S. (Orgs.). The Landscape of qualitative research. Thousand Oaks: Sage publications, 2008. p.1-44.

DICK, P.; COLLINGS, D. G. Discipline and punish? Strategy discourse, senior manager subjectivity and contradictory power effects. Human Relations, v. 67, n. 12, p. 1513-1536, 2014.

ENGELSTAD, F. Culture and Power. In: CLEGG, S.R. (Org.). The Sage Handbook of Power. London: Sage publications, 2009. p.210-238.

FARIA, J. H. DE. Análise de Discurso em Estudos Organizacionais: As concepções de Pêcheux e Bakhtin. XXXIX Encontro da Associação Nacional dos Programas de Pós-Graduação em Administração, 2015. Anais... . p.1-13. Belo Horizonte, 2015.

FLEMING, P. Down with Big Brother! The End of Corporate Culturalism? Journal of Management Studies, v. 50, n. 3, p. 474-495, 2013.

FLEMING, P.; SPICER, S. Contesting the corporation: Struggle, power and resistance. Cambridge: Cambridge University Press, 2007.

FOUCAULT, M. O Sujeito e o Poder. In: DREYFUS; H.; RABINOW, P. (Orgs.). Michel Foucault: Uma Trajetória Filosófica para além do Estruturalismo e a Hermenêutica. Rio de Janeiro: Forense Universitária, 1995. p.229-250.

FOUCAULT, M. Microfísica do Poder. 13. ed. Rio de Janeiro: Graal, 1998.

FOUCAULT, M. História da sexualidade: A Vontade do Saber. 13. ed. Rio de Janeiro: Graal, 1999a. v.I.

FOUCAULT, M. As Palavras e as Coisas. 8. ed. São Paulo: Martins Fontes, 1999b.

FOUCAULT, M. A verdade e as formas jurídicas. Rio de Janeiro: Nau, 2002.

FOUCAULT, M. Vigiar e punir: nascimento da prisão. Petrópolis: Vozes, 2004.

FOUCAULT, M. Em defesa da sociedade. São Paulo: Martins Fontes, 2005.

FOUCAULT, M. A arqueologia do saber. 7.ed. Rio de Janeiro: Forense Universitária, 2008a.

FOUCAULT, M. Segurança, território, população. São Paulo: Martins Fontes, 2008b.

FREITAS, M. E. DE. Cultura organizacional: identidade, sedução e carisma. Rio de Janeiro: Editora FGV, 2000.

FREITAS, M. E. DE. Ser ou estar acadêmico ? Organização \&Sociedade, v. 14, n. 43, p. 199-204, 2007a. 
FREITAS, M. E. DE. A carne e os ossos do ofício acadêmico. Organização \&Sociedade, v. 14, n. 42, p. 187-191, 2007b.

FREITAS, M. E. DE. Cultura organizacional: evolução e crítica. São Paulo: Thomson Learning, 2007c.

GEERTZ, C. The Interpretation of Cultures: Selected essays. New York: Basic Books, 1973.

GIORGI, S.; LOCKWOOD, C.; GLYNN, M. A. The many faces of culture: Making sense of 30 years of research on culture in organization studies. Academy of Management Annals, v. 9, n.1, p. $37-41,2015$.

GOMES, H. S. Justiça julga válida demissão com justa causa por "curtida" no Facebook. Disponível em: <http://g1.globo.com/tecnologia/noticia/2014/06/justica-julga-valida-demissao-com-justa-causa-por-curtida-no-facebook.html>. Acesso em: 29jun. 2015.

HALLETT, T. Symbolic Power and Organizational Culture. Sociological Theory, v. 21, n. 2, p. 128-149, 2003.

HARDY, C.; CLEGG, S. R. Alguns ousam chamá-lo de poder. In: CLEGG, S.R.; HARDY, C.; NORD, W. (Orgs.). Handbook de estudos organizacionais: reflexões e novas direções. São Paulo: Atlas, 2001. p.229-250.

HARDY, C.; GRANT, D. Readers beware: Provocation, problematization and ... problems. Human Relations, v. 65, n. 5, p. 547-566, 2012.

HARDY, C.; PHILLIPS, N. Discourse and Power. In: GRANT, D.; HARDY, C.; OSWICK, C.; PUTNAM, L. (Orgs.).The Sage Handbook of Organizational Discourse. . London: Sage publications, 2004. p.299-316.

HATCH, M. J.; CUNLIFFE, A. Organization theory: modern, symbolic and postmodern perspectives. New York: Oxford University Press, 2006.

JELINEK, M.; SMIRCICH, L.; HIRSCH, P. Introduction: A Code of Many Colors. Administrative Science Quarterly, v. 28, n. 3, p. 331-338, 1983.

LABATUT, J.; AGGERI, F.; GIRARD, N. Discipline and Change: How Technologies and Organizational Routines Interact in New Practice Creation. 2012.

LECLERCQ-VANDELANNOITTE, A. Organizations as Discursive Constructions: A Foucauldian Approach. Organization Studies, v. 32, n. 9, p. 1247-1271, 2011.

LYON, D.; HAGGERTY, K.; BALL, K. Introducing Surveillance Studies. In: KIRSTIE, B.;HAGGERTY, K.D.; DAVID, L. (Orgs.). Routledge Handbook of Surveillance Studies. New York: Routledge, 2012. p.1-11.

MARTINS, G. A.; THEÓPHILO, C. R. Metodologia da investigação cientifica para ciências sociais aplicadas. São Paulo: Atlas, 2009.

MARX, G. T. Your papers please: personal and professional encounters with surveillance. Routledge Handbook of Surveillance Studies, Routledge, Oxon, p. xxvi, 2012. 
MARX, G. T. Surveillance Studies. International Encyclopedia of the Social \& Behavioral Sciences. v. 23, p.733-741, 2015.

MCKINLAY, A.; CARTER, C.; PEZET, E. Governmentality, power and organization. Management \& Organizational History, v. 7, n. 1, p. 3-15, 2012.

MUMBY, D. K. What's cooking in organizational discourse studies? A response to Alvesson and Karreman. Human Relations, v. 64, n. 9, p. 1147-1161, 2011.

MUNRO, I. The Management of Circulations: Biopolitical Variations after Foucault. International Journal of Management Reviews, v. 14, n. 3, p. 345-362, 2012.

MURAD, I.; LOURENÇO, C. D. S.; NASCIMENTO, A. P. Poder e Conflito nas Organizações: O Caso de uma Empresa Familiar do Setor de Construção Civil. Administração: Ensino e Pesquisa, v. 18, n. 1, p. 125-152, 2017.

NEUMAN, W. L. Social reserach methods: qualitative and quantitative approachs. 7.ed. Boston: Pearson, 2009.

POMPPER, D. Experiencing culture inside and outside organizations, in Donnalyn Pompper (ed.) Practical and Theoretical Implications of Successfully Doing Difference in Organizations. International Perspectives on Equality, Diversity and Inclusion, v. 1, p.65-80, 2014.

PHILLIPS, N.; OSWICK, C. Organizational Discourse: Domains, Debates, and Directions. The Academy of Management Annals, v. 6, n. 1, p. 435-481, 2012.

RIAD, S. The Power of "Organizational Culture" as a Discursive Formation in Merger Integration. Organization Studies, v. 26, n. 10, p. 1529-1554, 2005.

RODRIGUEZ, J.; STEWART, P. HRM and work practices in Chile: the regulatory power of organizational culture. Employee Relations, v. 39, n. 3, p.378-390, 2017.

SAMPAIO, H. O setor privado de ensino superior no Brasil: Continuidades e transformações. Revista Ensino Superior Unicamp, v. 1, p. 28-43, 2011.

SEWELL, G. The Discipline of Teams: The Control of Team-Based Industrial Work through Electronic and Peer Surveillance. Administrative Science Quarterly, v. 43, n. 2, p. 397-428, 1998.

SEWELL, G. Organization, employees and surveillance. Routledge Handbook of Surveillance Studies. p.303, 2012.

SEWELL, G.; BARKER, J. R. Coercion versus care: Using irony to make sense of organizational surveillance. Academy of Management Review, v. 31, n. 4, p. 934-961, 2006.

SEWELL, G.; BARKER, J. R.; NYBERG, D. Working under intensive surveillance: When does "measuring everything that moves" become intolerable? Human Relations, v. 65, n. 2, p. $189-215,2012$.

STAKE, R. E. The art of case study research. London: Sage publications, 1995. 
STAKE, R. E. Qualitative research: studying how things work. New York: The Guilford Press, 2010.

TEIXEIRA, I. N. DE E. E P. E. A. Censo da Educação Superior 2016: Notas Estatísticas. Disponível em: < http:/ / portal.inep.gov.br/superior-censosuperior-sinopse>. Acesso em: $01 / 06 / 2017$.

TORELLI, C. J. et al. Justice or compassion? Cultural differences in power norms affect consumer satisfaction with power-holders. International Marketing Review, v. 32, n. 3/4, 2015.

TRICE, H. M.; BEYER, J. M. Studying organizational cultures through rites and ceremonials. Academy of Management Review, v. 9, n. 4, p. 653-669, 1984.

URETA, S. Waiting for the Barbarians: disciplinary devices on Metro de Santiago. Organization, v. 20, n. 4, p. 596-614, 2013.

VARELA, O.E.; SALGADO, E.I.; LASIO, M.V. The meaning of job performance in collectivistic and high power distance cultures: Evidence from three Latin American countries. Cross Cultural Management: An International Journal, v. 17 n. 4, p.407-426, 2010.

WAIANDT, C.; DAVEL, E. Sucessão e parceria em uma empresa capixaba de bebidas: durante o jantar. Revista Interdisciplinar de Gestão Social, v. 1, n. 2, p. 213-227, 2012.

WEISKOPF, R.; MUNRO, I. Management of human capital: discipline, security and controlled circulation in HRM. Organization, 2011.

WILLMOTT, H. Strength is Ignorance; Slavery is Freedom: Managing Culture in Modern Organizations. Journal of Management Studies, v. 30, n. 4, p. 515, 1993.

WILLMOTT, H. The Substitution of One Piece of Nonsense for Another: Reflections on Resistance, Gaming, and Subjugation. Journal of Management Studies, v. 50, n. 3, p. 443-473, 2013. 


\section{DADOS DOS AUTORES}

\section{André Maurício Teixeira da Silva ${ }^{\star}$ andremtsilva@yahoo.com}

Mestre em Administração pela UFPR

Instituição de vinculação: Universidade Federal do Paraná

Curitiba/PR - Brasil

Áreas de interesse em pesquisa: Cultura, identidade, poder, ensino em Administração.

* Tv. Ferreira do Amaral, 30 apto-503 Agua Verde Curitiba/PR 80620-090

\section{MARIANE LEMOS LOURENÇO psimari@uol.com.br}

\section{Doutora em Psicologia pela USP}

Instituição de vinculação: Universidade Federal do Paraná

Curitiba/PR - Brasil

Áreas de interesse em pesquisa: Cultura, identidade, poder, ensino em Administração. 